\title{
Histological and immunohistochemical studies on primary intracranial canine histiocytic sarcomas
}

\author{
Atigan THONGTHARB ${ }^{1}$, Kazuyuki UCHIDA ${ }^{1) *}$, James Kenn CHAMBERS ${ }^{1)}$, Yumiko KAGAWA ${ }^{2)}$ and \\ Hiroyuki NAKAYAMA ${ }^{1)}$ \\ 1) Department of Veterinary Pathology, Graduate School of Agricultural and Life Sciences, The University of Tokyo, 1-1-1 Yayoi, Bunkyo- \\ ku, Tokyo 113-8657, Japan \\ 2)North Lab, 8-35 Hondoori 2-chome Kita, Shiroishi-ku, Sapporo, Hokkaido 003-0027, Japan
}

(Received 30 October 2015/Accepted 1 December 2015/Published online in J-STAGE 12 December 2015)

ABSTRACT. Histiocytic sarcoma is a progressive and fatal malignant neoplasm that mainly occurs in middle- to old-aged dogs. This study describes clinicopathological, histological and immunohistochemical characteristics of intracranial histiocytic sarcomas in 23 dogs. Magnetic resonance imaging and/or computed tomography of the brains revealed that the tumors mainly located in the cerebrum, particularly the frontal lobe. Seizure was a predominant clinical sign in most of the cases. Histologically, the tumor cells were morphologically classified into round/polygonal- and spindle-shaped cell types. There was a significant association between tumor cell types and hemophagocytic activity $(P<0.05)$. However, there was no significant difference in other clinicopathological parameters and mitotic index between the 2 types. Immunohistochemically, tumor cells were strongly positive for HLA-DR, Iba-1 and CD204 in all the 23 cases, for iNOS in 20 , for CD163 in 17, for CD208 (DC-LAMP) in 9, for lysozyme in 8 and for S100 in 5 cases. In addition, the Ki67-proliferative index showed range of $0.50-64.33 \%$ (Average $26.60 \pm 3.81 \%$ ). These observations suggest that canine primary intracranial histiocytic sarcomas tend to exhibit both dendritic cell and macrophage phenotypes of histiocytic differentiation.

KEY WORDS: brain, canine, histiocytic sarcoma, immunohistochemistry

doi: 10.1292/jvms.15-0627; J. Vet. Med. Sci. 78(4): 593-599, 2016

Histiocytic proliferative disorders (HPDs) are currently well documented in human and various animal species, however, the etiology as well as pathogenesis is still unclear $[1-3,13,15,28]$. In the dog, HPDs were first described in 1970 s and recently classified into 3 major types including reactive histiocytosis (cutaneous and systemic forms), cutaneous histiocytoma and histiocytic sarcoma (localized and disseminated forms) depending upon clinical behaviors and pathological features $[6,9,19]$.

Canine histiocytic sarcoma (HS) included in HPDs, is a progressive and fatal malignant neoplasm that is mainly documented in middle-age to older purebred dogs, predominantly in the Bernese mountain dog, Retriever and Rottweiler $[1,6,9,19,24]$. Moreover, the Pembroke Welsh Corgi, Shetland sheepdog and other purebreds are also described sporadically [2, 11, 29, 30, 33]. In general, the histiocytes are divided into 2 cell types: dendritic cells (DCs) and macrophages. Most of the canine HS cases originate from DCs. Several cases arising from macrophages, namely hemophagocytic HS, are very rare [21, 25]. In accordance with the distribution pattern of tumor, the number of primary organ involved and the evidence of distant metastasis, HSs

*Correspondence to: Uchida, K., Department of Veterinary Pathology, Graduate School of Agricultural and Life Sciences, The University of Tokyo, 1-1-1 Yayoi, Bunkyo-ku, Tokyo 113-8657, Japan. e-mail: auchidak@mail.ecc.u-tokyo.ac.jp

(C)2016 The Japanese Society of Veterinary Science

This is an open-access article distributed under the terms of the Creative Commons Attribution Non-Commercial No Derivatives (by-nc-nd) License $<$ http://creativecommons.org/licenses/by-nc-nd/4.0/>. are classified into localized and disseminated forms. The localized form is recognized as a solitary mass that mainly manifests in the skin and subcutis of the extremities with local invasion to sentinel lymph nodes. In the disseminated form, on the contrary, multiple masses occur preferentially in the spleen, lung and bone marrow with a rapid and widespread metastasis [2].

The incidence of HS with the central nervous system (CNS) involvement is very low in both human and animals. In veterinary literatures, to our knowledge, there have been only 10 publications describing the occurrence of HS with CNS manifestation [5, 11, 12, 16, 26-30, 33]. Like the distribution pattern of HS in the extraneural tissues, both localized and disseminated HSs are being observed in the CNS tissues. Ide et al. [11] mentioned that the cellular morphologies of both localized and disseminated HSs in CNS were histologically identical. Moreover, immunohistochemical expression patterns of those were not associated with the tumor cell of origin. HS cases with the CNS involvement exhibited mainly histiocytic markers, such as major histocompatibility complex class II (MHC II), lysozyme and CD18. Currently, most of the histiocytic markers provided to confirm cellular origin of HS are only available for frozen tissue samples. Furthermore, the cellular origin and histogenesis of HS in the CNS are still unclear due to the low incidence. In the present study, therefore, we describe clinicopathological, histological and immunohistochemical (IHC) characteristics of intracranial histiocytic sarcomas in 23 dogs by using conventional diagnostic markers. In addition, inducible nitric oxide synthase (iNOS) and dendritic cell-lysosomal associated membrane protein (DC-LAMP or CD208) were 
employed as macrophage and dendritic cell markers, respectively. The Ki67-proliferative index (PI) was also illustrated in all the samples.

\section{MATERIALS AND METHODS}

Samples: Formalin-fixed canine brain tumor samples including 20 tumor biopsies and 3 necropsies between 2009 and 2014 were pathologically examined at the Department of Veterinary Pathology, Graduate School of Agricultural and Life Sciences, the University of Tokyo. All the cases were histologically diagnosed as HS. The signalment, neurological signs and tumor location of the 23 dogs are summarized in Table 1.

Histology: Two to four $-\mu \mathrm{m}$ thick paraffin tissue sections were stained with hematoxylin and eosin (HE). The tumors were morphologically divided into 2 categories (round/ polygonal and spindle cell types) as described previously [6]. In the present study, conversely, multinucleated giant cells were included in round/polygonal cell type. In order to determine the mitotic index (MI), 10 highest densities of mitotic figure areas were randomly selected, and then, the total number of mitoses was counted per 10 high power fields (hpf; 400X).

Immunohistochemistry: Primary antibodies used for immunohistochemistry (IHC) and antigen retrieval methods are detailed in Table 2. In order to block non-specific reactions, all tissue sections were immersed in $10 \%$ hydrogen peroxide $\left(\mathrm{H}_{2} \mathrm{O}_{2}\right)$ in methanol at room temperature for $5 \mathrm{~min}$ and then incubated in $8 \%$ skim milk at $37^{\circ} \mathrm{C}$ for $30 \mathrm{~min}$. All tissue sections were applied with each primary antibody at $4^{\circ} \mathrm{C}$ overnight. The Envision ${ }^{+}$system-HRP labeled polymer reagent (DAKO, Tokyo, Japan) was then applied at $37^{\circ} \mathrm{C}$ for $40 \mathrm{~min}$. For the detection of CD208, tissue sections were applied with a biotinylated secondary antibody (1:400, antirat $\operatorname{IgG}(\mathrm{H}+\mathrm{L})$ antibody, KPL, Gaithersburg, MD, U.S.A.) at $37^{\circ} \mathrm{C}$ for $1 \mathrm{hr}$ and then incubated with streptavidin/HRP reagent $(1: 300, \mathrm{DAKO})$ at room temperature for $40 \mathrm{~min}$. All sections were rinsed with Tris-buffered saline (TBS) prior to treat with 3-3'-diaminobenzidine solution containing $0.03 \%$ $\mathrm{H}_{2} \mathrm{O}_{2}$ and the counterstained with Mayer's hematoxylin (Muto Pure Chemicals, Tokyo, Japan). Normal canine tissues were used as positive controls, whereas negative controls were performed through applying with TBS instead of the primary antibodies. Positive tumor cells were counted in randomly selected areas (hpf; 400X). Semiquantitative scores included 4 categories as follows: $-($ Negative $)=$ no positive tumor cells; + (Weakly positive $)=1-25 \%$ positive tumor cells; ++ (Moderately positive $)=26-50 \%$ positive tumor cells; $+++($ Strongly positive $)=>50 \%$ positive tumor cells. In addition, the Ki67 expression was also determined by counting the number of nuclear positive in the HS cells among total numbers of HS cells in 10 random hpf fields (400X). The average percentage of those was defined as Ki67-PI.

Statistical analyses: Chi-square or Fisher's exact test was used to assess the association between clinicopathological features together with hemophagocytic activity and necrosis, and morphological difference of tumor cells, as appropriate. The percentage of Ki67-positive tumor cells was demonstrated as range and mean \pm standard error of the mean (SEM). In addition, Mann-Whitney $U$ test was performed to determine the significance of difference of mean MI and Ki67-PI between two cell types. Two-sided significant level was used that $P$-value $<0.05$ was considered statistically significant.

\section{RESULTS}

Tumor occurrence: Twenty three dogs examined were 14 males and 9 females with the median age of 9 years ( 4 years to 14 years). Breeds were comprised of Pembroke Welsh Corgi $(n=11)$, Shetland sheepdog $(n=3)$, Labrador retriever $(n=2)$, Beagle $(n=2)$, mixed breed $(n=2)$, Flat coated retriever $(n=1)$, Miniature schnauzer $(n=1)$ and Siberian husky $(n=1)$. Various neurological signs were recorded in 19 dogs, which included seizure $(n=12)$, altered level of consciousness $(n=5)$, circling $(n=5)$, abnormal basic vision test $(n=4)$, gait abnormalities $(n=4)$, proprioceptive deficits $(n=4)$, hemiplegia and paralysis $(n=3)$, disorientation $(n=2)$, head pressing $(n=2)$, head tilt $(n=2)$, tremor $(n=2)$, behavioral change $(n=1)$ and somnolence $(n=1)$. Brain magnetic resonance imaging (MRI) and/or computed tomography (CT) were also performed in all the cases to detect tumor distribution. Most of the tumors $(n=21)$ were observed in the cerebrum, whereas two cases (Case Nos. 4 and 15) were in the cerebellum. Complete postmortem examination was performed only in Case Nos. 4, 5 and 15, and as far as examined in the 3 cases, tumor invasions to distant organs were not detected.

Histological examination: Microscopically, brain masses of all cases were poorly demarcated and invading to the brain parenchyma. The tumor cells were classified into 2 types in accordance with cellular morphology. The first type was defined by round- to pleomorphic-shaped cells with eosinophilic cytoplasm and distinct border. Cytoplasmic vacuolation was occasionally found. These cells had eccentric, round to ovoid nuclei with prominent nucleoli (1-2 nucleoli/ nucleus). Marked anisocytosis and anisokaryosis were noted with various numbers of atypical mitoses. Multinucleated giant tumor cells were frequently found. Hemophagocytic activity was commonly observed in almost all the cases of this type (Fig. 1 and Table 3 ). The second type was defined by spindle- and fusiform-shaped cells with indistinct border. These cells arranged in irregular pattern. Their nuclei were ovoid to spindle shaped and concentrically located. The nucleoli were obscure. Mild anisocytosis and anisokaryosis, and atypical mitoses were noted (Fig. 2). Hemophagocytosis was seen in only one dog (Case No. 23). In both tumor types, moderated to marked infiltration of small lymphocytes was notably observed surrounding small-sized blood vessels and scattering throughout the neoplastic lesions. Moderate necrosis was occasionally found. Moreover, we found statistically significant associations between tumor cell types and hemophagocytic activity $(P<0.05)$. However, there were no significant differences in other clinicopathological parameters (age, sex and necrosis) and MI between the two cell 


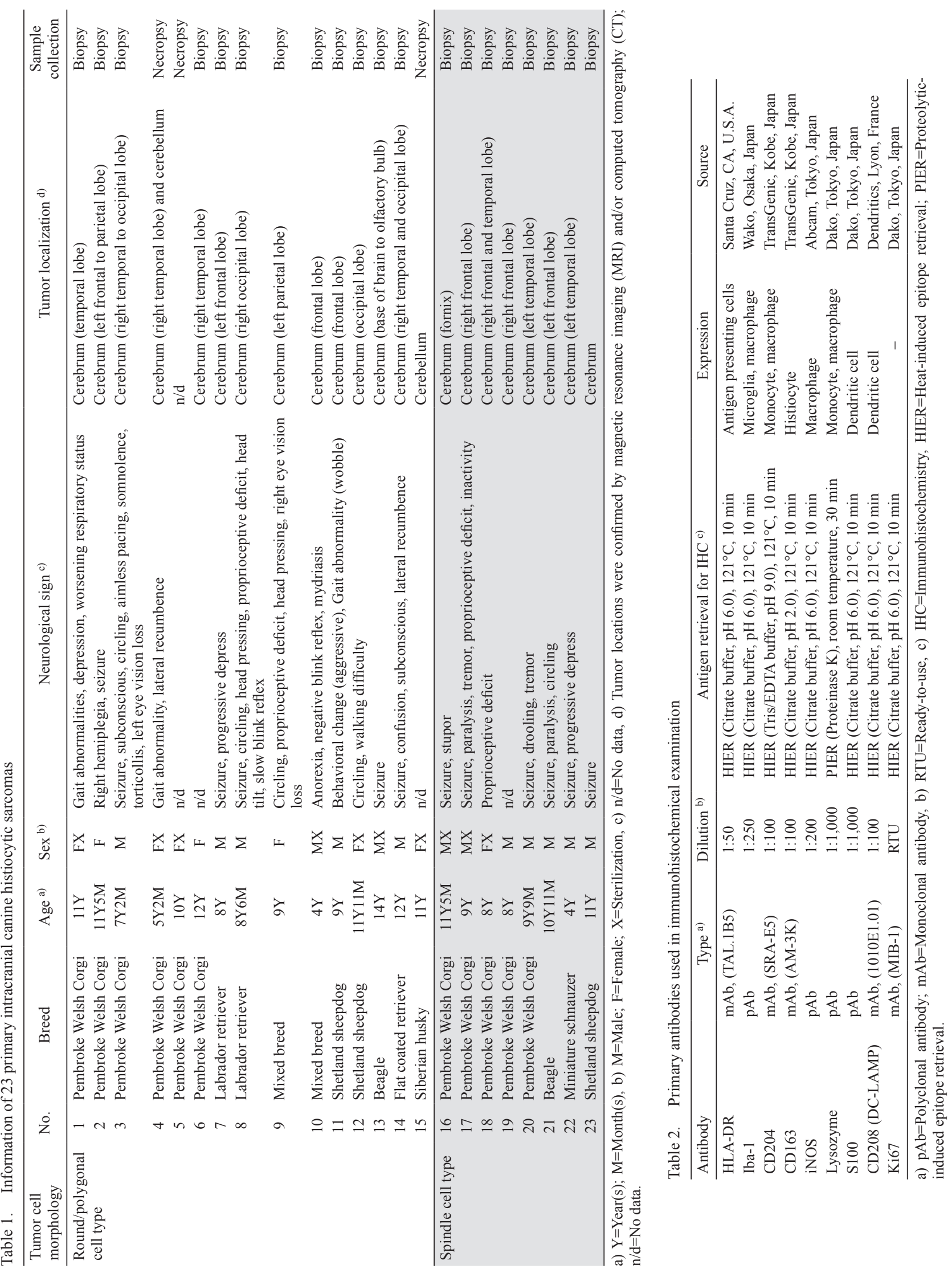


Table 3. Histological and immunohistochemical features of primary intracranial canine histiocytic sarcomas

\begin{tabular}{|c|c|c|c|c|c|c|c|c|c|c|c|c|c|c|}
\hline \multirow{2}{*}{ No. } & \multirow{2}{*}{ Breed } & \multirow{2}{*}{ Tumor cell morphologya) } & \multirow{2}{*}{$\mathrm{MI}^{\mathrm{b})}$} & \multirow{2}{*}{$\begin{array}{l}\text { Hemophago- } \\
\text { cytosis }^{c)}\end{array}$} & \multirow{2}{*}{ Necrosis $\left.{ }^{d}\right)$} & \multicolumn{9}{|c|}{ IHC results ${ }^{\mathrm{e})}$} \\
\hline & & & & & & HLA-DR & Iba-1 & CD204 & CD163 & iNOS & Lysozyme & $\mathrm{S} 100$ & CD208 & Ki67 (\%) \\
\hline 1 & Pembroke Welsh Corgi & Round/polygonal cell type & 4 & + & - & +++ & +++ & +++ & - & +++ & - & - & +++ & 30.08 \\
\hline 2 & Pembroke Welsh Corgi & Round/polygonal cell type & 33 & - & + & +++ & +++ & +++ & +++ & +++ & +++ & + & +++ & 53.29 \\
\hline 3 & Pembroke Welsh Corgi & Round/polygonal cell type & 56 & + & + & +++ & +++ & +++ & ++ & +++ & +++ & + & - & 26.00 \\
\hline 4 & Pembroke Welsh Corgi & Round/polygonal cell type & 22 & + & + & +++ & +++ & +++ & +++ & +++ & +++ & - & - & 29.52 \\
\hline 5 & Pembroke Welsh Corgi & Round/polygonal cell type & 8 & + & - & +++ & +++ & +++ & ++ & + & +++ & - & - & 3.00 \\
\hline 6 & Pembroke Welsh Corgi & Round/polygonal cell type & 32 & - & + & +++ & +++ & ++ & +++ & +++ & +++ & - & + & 64.33 \\
\hline 7 & Labrador retriever & Round/polygonal cell type & 39 & + & - & +++ & +++ & +++ & +++ & +++ & +++ & - & ++ & 32.86 \\
\hline 8 & Labrador retriever & Round/polygonal cell type & 37 & - & + & +++ & +++ & +++ & ++ & +++ & - & + & - & 15.68 \\
\hline 9 & Mixed breed & Round/polygonal cell type & 70 & + & + & +++ & +++ & +++ & +++ & +++ & - & - & - & 49.05 \\
\hline 10 & Mixed breed & Round/polygonal cell type & 44 & - & + & +++ & +++ & +++ & - & + & - & - & - & 5.67 \\
\hline 11 & Shetland sheepdog & Round/polygonal cell type & 24 & + & - & +++ & +++ & +++ & - & + & - & - & + & 38.41 \\
\hline 12 & Shetland sheepdog & Round/polygonal cell type & 62 & + & + & +++ & +++ & ++ & ++ & - & - & - & - & 6.50 \\
\hline 13 & Beagle & Round/polygonal cell type & 4 & + & + & +++ & +++ & +++ & +++ & - & - & + & ++ & 0.50 \\
\hline 15 & Siberian Husky & Round/polygonal cell type & 0 & + & + & +++ & +++ & +++ & - & +++ & +++ & - & ++ & 2.00 \\
\hline 16 & Pembroke Welsh Corgi & Spindle cell type & 58 & - & + & +++ & +++ & +++ & +++ & +++ & +++ & - & - & 23.37 \\
\hline 17 & Pembroke Welsh Corgi & Spindle cell type & 26 & - & - & +++ & +++ & +++ & +++ & ++ & - & - & - & 32.99 \\
\hline 18 & Pembroke Welsh Corgi & Spindle cell type & 11 & - & + & +++ & +++ & +++ & - & - & - & - & - & 42.38 \\
\hline 19 & Pembroke Welsh Corgi & Spindle cell type & 10 & - & + & +++ & +++ & +++ & +++ & + & - & - & - & 18.88 \\
\hline 20 & Pembroke Welsh Corgi & Spindle cell type & 44 & - & + & +++ & +++ & +++ & +++ & ++ & - & - & - & 48.82 \\
\hline 21 & Beagle & Spindle cell type & 7 & - & - & +++ & +++ & +++ & ++ & + & - & - & ++ & 26.68 \\
\hline 22 & Miniature schnauzer & Spindle cell type & 6 & - & + & +++ & +++ & +++ & +++ & + & - & - & ++ & 18.35 \\
\hline 23 & Shetland sheepdog & Spindle cell type & 12 & + & + & +++ & +++ & +++ & - & ++ & - & + & - & 2.75 \\
\hline Tot: & & & & & & 23 & 23 & 23 & 17 & 20 & 8 & 5 & 9 & \\
\hline
\end{tabular}

a) Round/polygonal cell type $=>50 \%$ of tumor cell population are neoplastic histiocytes and multinucleated giant cells; Spindle cell type $=>50 \%$ of tumor cell population are spindle-shaped cells, b) Mitotic index=Number of mitotic figures per 10 high power fields, c) Hemophagocytosis score: +=Hemophagocytosis is present; $-=$ Hemophagocytosis is absent, d) Necrosis score: +=Necrotic area is observed; $-=$ No necrotic area is observed, e) Immunohistochemical scoring: $-($ Negative $)=$ Negative tumor cells;

$+($ Weakly positive $)=1-25 \%$ positive tumor cells; $++($ Moderately positive $)=26-50 \%$ positive tumor cells; $+++($ Strongly positive $)=>50 \%$ positive tumor cells.

types (Table 4). Based on histological results, the diagnoses of HS were made in all the cases.

Immunohistochemistry: Intense cell membrane and/or cytoplasmic immunoreactivities to HLA-DR, Iba-1 and CD204 were observed in all 23 tumors (100.00\%). Diffuse cytoplasmic staining for iNOS was detected in 20 cases $(86.96 \%)$. Tumor cells in 17 cases $(73.91 \%)$ were positive for CD163 with strong membrane staining. Nine tumors (39.13\%) exhibited focal to diffuse cytoplasmic staining for CD208. Eight tumors $(34.78 \%)$ exhibited cytoplasmic staining for lysozyme. Variable or weak cytoplasmic S100 immunoreaction was noted in 5 cases $(21.74 \%)$ (Fig. 3 and Table 3 ). Ki67-PI of HS with CNS involvement ranged 0.50-64.33\% (average $26.60 \pm 3.81 \%$ ). However, there was no significant difference in Ki67-PI between round/polygonal and spindle cell types.

\section{DISCUSSION}

Despite canine histiocytic sarcoma has been well documented over the past several years, there have been only 10 publications demonstrating the occurrence of HS in the CNS. In the present study, HS in the brain was frequently found in Pembroke Welsh Corgis, which is consistent with the results of previous studies [11, 16, 29]. Seizure is the major neurological sign of the cases of HS in the brain, while other clinical signs were found sporadically. A variety of the clinical signs might be associated with the affected areas of the brain. Based on clinical histories and diagnostic imaging results, the tumor invasion and metastasis to other distant organs were not detected, supporting that the brains are the primary site of HS in all the present 23 cases. Furthermore, in accordance with tumor distribution, only the localized pattern was observed in all the present cases, supporting that localized HS might be main form of intracranial HS in dog as described previously $[5,11,29,33]$.

Tumor cells were infiltrated to brain parenchyma in all cases. The term of primary intracranial canine HS, therefore, applies to the present study. McMenamin et al. [18] demonstrated that antigen presenting cells were commonly found in the meninges and choroid plexus of normal rat brains and that the cells have similar immunophenotype and ultrastructural characteristics to DC. In accordance with the results of the present study, we postulate that the cellular origin of canine HS in the brain is possibly resident DC in either the meninges or choroid plexus.

The lesions of canine HS in the brain can be histologically classified into 2 types (round/polygonal and spindle cell types) like those in the spleen and extremities described previously [6]. Interestingly, the present results showed hemophagocytic activity of round/polygonal cell type was significantly higher than that of spindle cell type, suggesting 


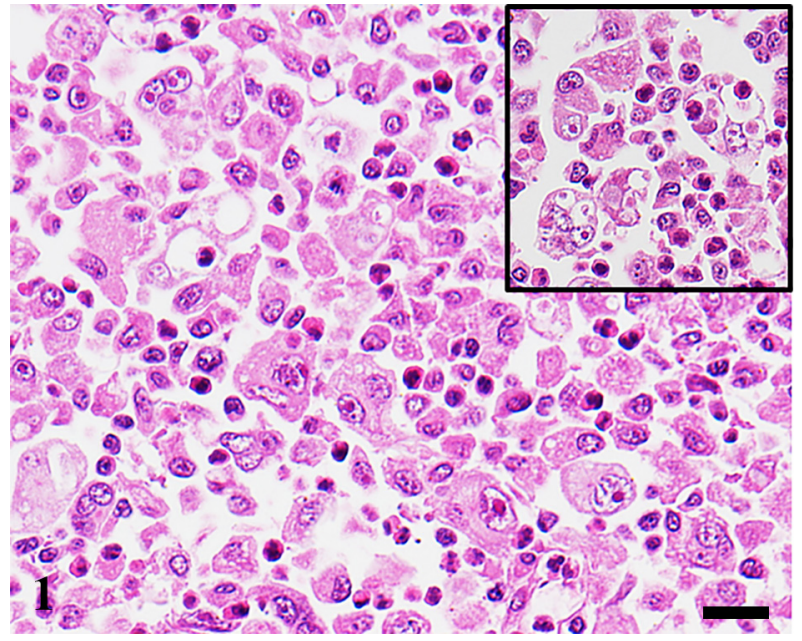

Fig. 1. Cerebellum. Dog. Case No. 4. Histiocytic sarcoma. Numerous polygonal to pleomorphic shaped neoplastic histiocytes proliferate in the brain parenchyma. Hemophagocytosis is commonly seen (inset). HE. Scale bar $=20 \mu \mathrm{m}$.

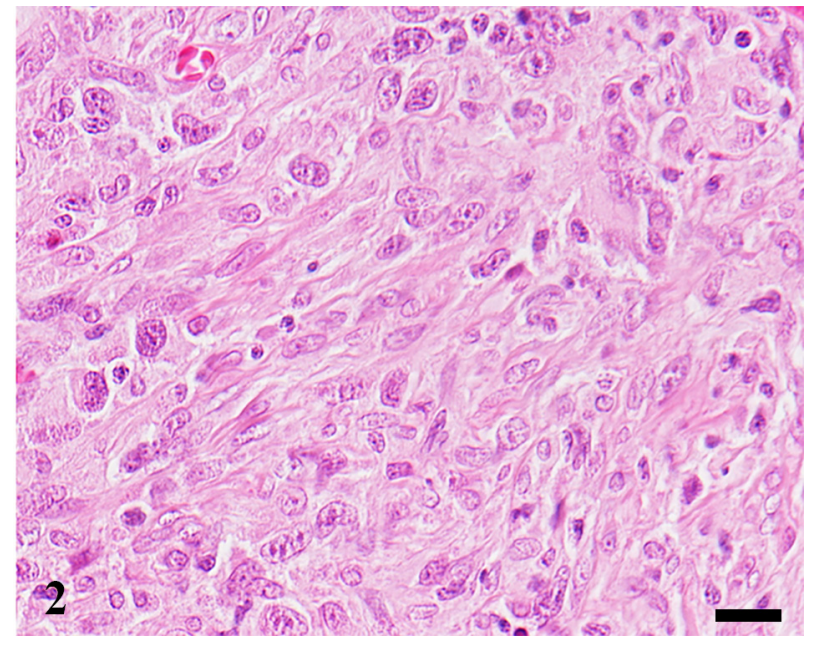

Fig. 2. Cerebrum. Dog. Case No. 20. Histiocytic sarcoma. Most of the tumor cells are spindle-shaped. HE. Scale bar $=20 \mu \mathrm{m}$.
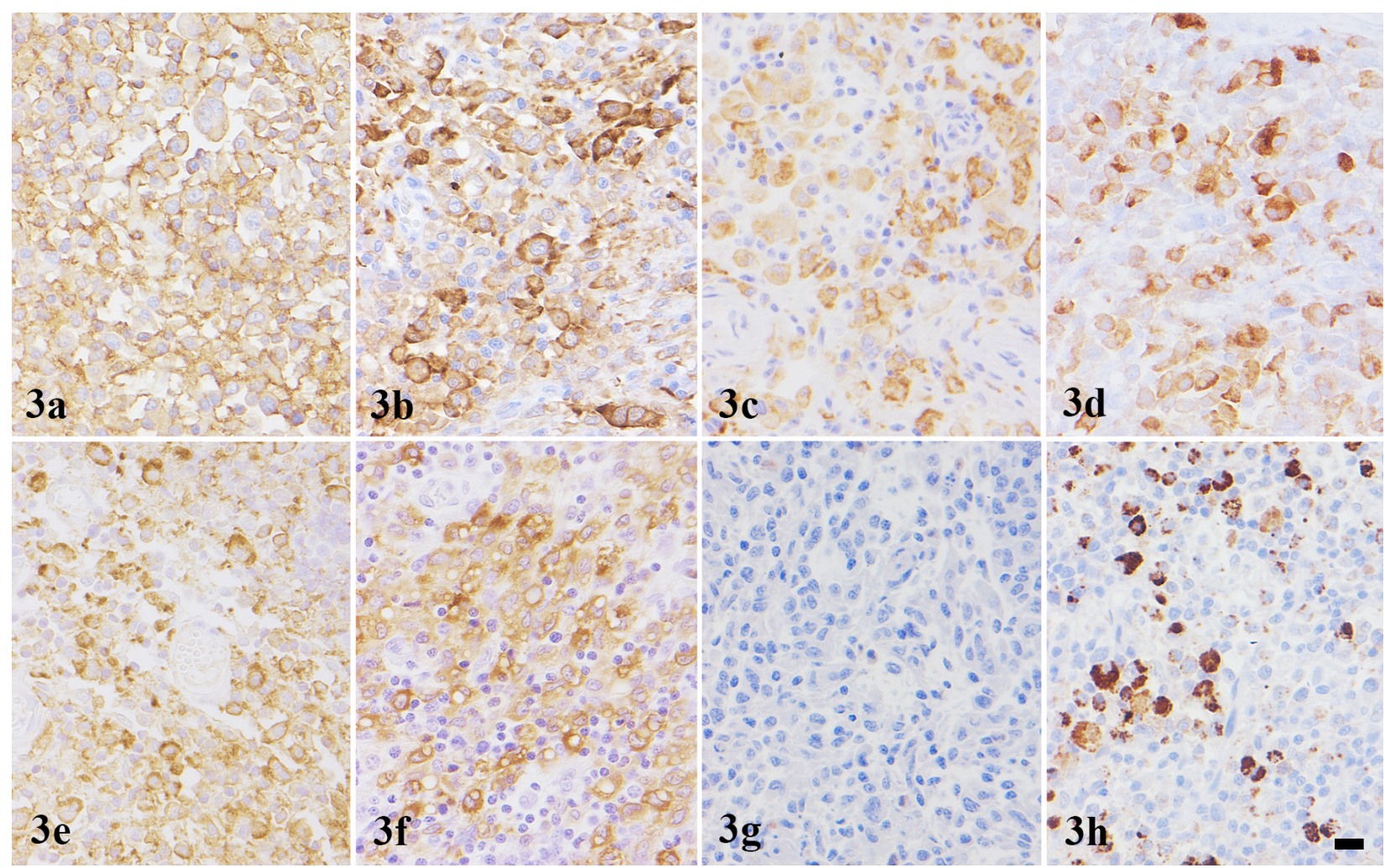

Fig. 3. Histiocytic sarcoma. Cerebrum; Dog. Case No. 6. Neoplastic histiocytes are positive for (a) HLA-DR, (b) Iba-1, (c) CD204, (d) CD163, (e) iNOS, (f) lysozyme and (h) CD208, but negative for (g) S100. IHC. Hematoxylin counterstain. Scale bar $=10 \mu \mathrm{m}$.

that the biological behaviors of round/polygonal-shaped cell type are probably more aggressive than another. However, there were no significant differences in sex, age, the presence of necrosis, Ki67-PI and the expression of immunohis- tochemical markers of tumor cells (data not shown) between the 2 types. These results support that the difference of tumor cell morphology cannot be used as histological predictive parameter for primary intracranial HS in dog, unlike HS 
Table 4. The association between clinicopathological characteristics and cellular morphology of primary intracranial canine histiocytic sarcoma

\begin{tabular}{|c|c|c|c|}
\hline Variable $^{\text {a) }}$ & $\begin{array}{l}\text { Round/polygonal cell type } \\
\qquad(\mathrm{n}=15)\end{array}$ & $\begin{array}{l}\text { Spindle cell type } \\
\qquad(\mathrm{n}=8)\end{array}$ & $P$-value ${ }^{\text {b) }}$ \\
\hline \multicolumn{4}{|l|}{ Sex } \\
\hline Male & 7 & 7 & 0.086 \\
\hline Female & 8 & 1 & \\
\hline \multicolumn{4}{|l|}{ Age range } \\
\hline$<3$ years & 0 & 0 & 1.000 \\
\hline$\geq 3$ years, $<6$ years & 2 & 1 & \\
\hline$\geq 6$ years & 13 & 7 & \\
\hline \multicolumn{4}{|l|}{ Tumor location } \\
\hline Cerebrum & 13 & 8 & 0.558 \\
\hline Cerebellum & 1 & 0 & \\
\hline $\mathrm{n} / \mathrm{d}$ & 1 & 0 & \\
\hline Hemophagocytosis (Presence) & 11 & 1 & $0.009^{b)}$ \\
\hline Necrosis (Presence) & 10 & 6 & 1.000 \\
\hline
\end{tabular}

a) $\mathrm{n} / \mathrm{d}=$ No data, b) $P<0.05$.

cases of extraneural tissues [6].

Lysozyme is widely used as a histiocytic marker in both human and animal to substantiate a diagnosis of histiocytic disorders. In human histiocytic disorders, the tumors that originated from macrophage lineage exhibited high expression of lysozyme, whereas those arose from DC had low expression or devoid of this molecule [4, 10, 17, 20, 31]. In the present study, intense lysozyme-immunoreactivity was observed in 8 dogs, supporting that these tumors had macrophage phenotype. On the other hands, S100 and CD208 are used as a marker for human DCs. The S100 molecule is specifically expressed by DC lineage except for follicular DCs, whereas the latter is exclusively expressed by human mature DCs and closely associated with DC differentiation and maturation [7, 23]. In the present study, S100 and CD208 immunoreactivities were observed in 5 and 9 tumors, respectively, supporting that these tumors had DC phenotype. HLA-DR, Iba-1 and CD204 immunoreactivity was detected in all 23 cases, confirming that the tumors originated from histiocytes [9, 14, 22]. In 20 cases, iNOS was detected, and CD163 in 17 cases; as the two molecules are widely used as M1 and M2 macrophage markers, respectively [8, 32]. The results showed that 15 cases of primary intracranial HS showed both iNOS ${ }^{+}$and $\mathrm{CD} 63^{+}(15 / 23)$, suggesting that the HS cells of the brain belong to the M1 and M2 macrophage phenotypes. However, some of intracranial HS cases (7/23) exhibited either M1 or M2 macrophage phenotype, and one case was negative for both macrophage and DC markers. These observations suggest that variable immunophenotypic features might be associated with the differentiation stage of the tumor cells.

Primary HS of the CNS is an aggressive malignant neoplasm, which has a worse prognosis. This tumor is the leading cause of cancer-related death in both human and animal. In accordance with all the present results, we can conclude that canine HS in the brain may in part possess the features of both macrophage and DC. However, M1 and M2 types are relatively predominant compared to the DC phenotype.
This phenomenon was also found in HS cases of extraneural tissues, but was an uncommon event [19]. Therefore, a number of samples including fresh/frozen primary brain tumor tissues and further in vitro studies are required in order to further verify cellular origins of canine HS arising in the CNS.

ACKNOWLEDGMENT. This study was supported in part by JSPS KAKENHI Grant Numbers 2629157 and 26660236.

\section{REFERENCES}

1. Abadie, J., Hédan, B., Cadieu, E., De Brito, C., Devauchelle, P., Bourgain, C., Parker, H. G., Vaysse, A., Margaritte-Jeannin, P., Galibert, F., Ostrander, E. A. and André, C. 2009. Epidemiology, pathology, and genetics of histiocytic sarcoma in the Bernese mountain dog breed. J. Hered. 100 Suppl 1: S19-S27. [Medline] [CrossRef]

2. Affolter, V. K. and Moore, P. F. 2002. Localized and disseminated histiocytic sarcoma of dendritic cell origin in dogs. Vet. Pathol. 39: 74-83. [Medline] [CrossRef]

3. Allen, C. E., Ladisch, S. and McClain, K. L. 2015. How I treat Langerhans cell histiocytosis. Blood 126: 26-35. [Medline] [CrossRef]

4. Beckstead, J. H., Wood, G. S. and Turner, R. R. 1984. Histiocytosis X cells and Langerhans cells: enzyme histochemical and immunologic similarities. Hum. Pathol. 15: 826-833. [Medline] [CrossRef]

5. Chandra, A. M. S. and Ginn, P. E. 1999. Primary malignant histiocytosis of the brain in a dog. J. Comp. Pathol. 121: 77-82. [Medline] [CrossRef]

6. Constantino-Casas, F., Mayhew, D., Hoather, T. M. and Dobson, J. M. 2011. The clinical presentation and histopathologicimmunohistochemical classification of histiocytic sarcomas in the Flat Coated Retriever. Vet. Pathol. 48: 764-771. [Medline] [CrossRef]

7. de Saint-Vis, B., Vincent, J., Vandenabeele, S., Vanbervliet, B., Pin, J. J., Aït-Yahia, S., Patel, S., Mattei, M. G., Banchereau, J., Zurawski, S., Davoust, J., Caux, C. and Lebecque, S. 1998. A novel lysosome-associated membrane glycoprotein, DC-LAMP, 
induced upon DC maturation, is transiently expressed in MHC class II compartment. Immunity 9: 325-336. [Medline] [CrossRef]

8. Edin, S., Wikberg, M. L., Dahlin, A. M., Rutegård, J., Öberg, A., Oldenborg, P. A. and Palmqvist, R. 2012. The distribution of macrophages with a M1 or M2 phenotype in relation to prognosis and the molecular characteristics of colorectal cancer. PLoS ONE 7: e47045. [Medline] [CrossRef]

9. Fulmer, A. K. and Mauldin, G. E. 2007. Canine histiocytic neoplasia: an overview. Can. Vet. J. 48: 1041-1043, 1046-1050. [Medline]

10. Hage, C., Willman, C. L., Favara, B. E. and Isaacson, P. G. 1993. Langerhans' cell histiocytosis (histiocytosis X): immunophenotype and growth fraction. Hum. Pathol. 24: 840-845. [Medline] [CrossRef]

11. Ide, T., Uchida, K., Kagawa, Y., Suzuki, K. and Nakayama, H. 2011. Pathological and immunohistochemical features of subdural histiocytic sarcomas in 15 dogs. J. Vet. Diagn. Invest. 23: 127-132. [Medline] [CrossRef]

12. Johnson, G. C., Coates, J. R. and Wininger, F. 2014. Diagnostic immunohistochemistry of canine and feline intracalvarial tumors in the age of brain biopsies. Vet. Pathol. 51: 146-160. [Medline] [CrossRef]

13. Juvet, S. C., Hwang, D. and Downey, G. P. 2010. Rare lung diseases III: pulmonary Langerhans' cell histiocytosis. Can. Respir. $J$. 17: e55-e62. [Medline]

14. Kato, Y., Murakami, M., Hoshino, Y., Mori, T., Maruo, K., Hirata, A., Nakagawa, T. L. D. R., Yanai, T. and Sakai, H. 2013. The class A macrophage scavenger receptor CD204 is a useful immunohistochemical marker of canine histiocytic sarcoma. $J$. Comp. Pathol. 148: 188-196. [Medline] [CrossRef]

15. Margo, C. E. and Goldman, D. R. 2008. Langerhans cell histiocytosis. Surv. Ophthalmol. 53: 332-358. [Medline] [CrossRef]

16. Mariani, C. L., Jennings, M. K., Olby, N. J., Borst, L. B., Brown, J. C. Jr., Robertson, I. D., Seiler, G. S. and MacKillop, E. 2015. Histiocytic sarcoma with central nervous system involvement in dogs: 19 cases (2006-2012). J. Vet. Intern. Med. 29: 607-613. [Medline] [CrossRef]

17. Mason, D. Y. and Taylor, C. R. 1975. The distribution of muramidase (lysozyme) in human tissues. J. Clin. Pathol. 28: 124-132. [Medline] [CrossRef]

18. McMenamin, P. G., Wealthall, R. J., Deverall, M., Cooper, S. J. and Griffin, B. 2003. Macrophages and dendritic cells in the rat meninges and choroid plexus: three-dimensional localisation by environmental scanning electron microscopy and confocal microscopy. Cell Tissue Res. 313: 259-269. [Medline] [CrossRef]

19. Moore, P. F. 2014. A review of histiocytic diseases of dogs and cats. Vet. Pathol. 51: 167-184. [Medline] [CrossRef]

20. Moore, P. F. 1986. Utilization of cytoplasmic lysozyme immunoreactivity as a histiocytic marker in canine histiocytic disorders. Vet. Pathol. 23: 757-762. [Medline]

21. Moore, P. F., Affolter, V. K. and Vernau, W. 2006. Canine hemophagocytic histiocytic sarcoma: a proliferative disorder of CD11d+ macrophages. Vet. Pathol. 43: 632-645. [Medline] [CrossRef]
22. Pierezan, F., Mansell, J., Ambrus, A. and Rodrigues Hoffmann, A. 2014. Immunohistochemical expression of ionized calcium binding adapter molecule 1 in cutaneous histiocytic proliferative, neoplastic and inflammatory disorders of dogs and cats. $J$. Comp. Pathol. 151: 347-351. [Medline] [CrossRef]

23. Pileri, S. A., Grogan, T. M., Harris, N. L., Banks, P., Campo, E., Chan, J. K., Favera, R. D., Delsol, G., De Wolf-Peeters, C., Falini, B., Gascoyne, R. D., Gaulard, P., Gatter, K. C., Isaacson, P. G., Jaffe, E. S., Kluin, P., Knowles, D. M., Mason, D. Y., Mori, S., Müller-Hermelink, H. K., Piris, M. A., Ralfkiaer, E., Stein, H., Su, I. J., Warnke, R. A. and Weiss, L. M. 2002. Tumours of histiocytes and accessory dendritic cells: an immunohistochemical approach to classification from the International Lymphoma Study Group based on 61 cases. Histopathology 41: 1-29. [Medline] [CrossRef]

24. Rossi, S., Gelain, M. E. and Comazzi, S. 2009. Disseminated histiocytic sarcoma with peripheral blood involvement in a Bernese Mountain dog. Vet. Clin. Pathol. 38: 126-130. [Medline] [CrossRef]

25. Soare, T., Noble, P. J., Hetzel, U., Fonfara, S. and Kipar, A. 2012. Paraneoplastic syndrome in haemophagocytic histiocytic sarcoma in a dog. J. Comp. Pathol. 146: 168-174. [Medline] [CrossRef]

26. Suzuki, M., Uchida, K., Morozumi, M., Yanai, T., Nakayama, H., Yamaguchi, R. and Tateyama, S. 2003. A comparative pathological study on granulomatous meningoencephalomyelitis and central malignant histiocytosis in dogs. J. Vet. Med. Sci. 65: 1319-1324. [Medline] [CrossRef]

27. Tamura, S., Tamura, Y., Nakamoto, Y., Ozawa, T. and Uchida, K. 2009. MR imaging of histiocytic sarcoma of the canine brain. Vet. Radiol. Ultrasound 50: 178-181. [Medline] [CrossRef]

28. Thio, T., Hilbe, M., Grest, P. and Pospischil, A. 2006. Malignant histiocytosis of the brain in three dogs. J. Comp. Pathol. 134: 241-244. [Medline] [CrossRef]

29. Tzipory, L., Vernau, K. M., Sturges, B. K., Zabka, T. S., Highland, M. A., Petersen, S. A., Wisner, E. R., Moore, P. F. and Vernau, W. 2009. Antemortem diagnosis of localized central nervous system histiocytic sarcoma in 2 dogs. J. Vet. Intern. Med. 23: 369-374. [Medline] [CrossRef]

30. Uchida, K., Morozumi, M., Yamaguchi, R. and Tateyama, S. 2001. Diffuse leptomeningeal malignant histiocytosis in the brain and spinal cord of a Tibetan Terrier. Vet. Pathol. 38: 219-222. [Medline] [CrossRef]

31. Yang, G. C. H., Besanceney, C. E. and Tam, W. 2010. Histiocytic sarcoma with interdigitating dendritic cell differentiation: a case report with fine needle aspiration cytology and review of literature. Diagn. Cytopathol. 38: 351-356. [Medline]

32. Zhang, M., He, Y., Sun, X., Li, Q., Wang, W., Zhao, A. and Di, W. 2014. A high M1/M2 ratio of tumor-associated macrophages is associated with extended survival in ovarian cancer patients. $J$ Ovarian Res. 7: 19. [Medline] [CrossRef]

33. Zimmerman, K., Almy, F., Carter, L., Higgins, M., Rossmeisl, J., Inzana, K. and Duncan, R. 2006. Cerebrospinal fluid from a 10-year-old dog with a single seizure episode. Vet. Clin. Pathol. 35: 127-131. [Medline] [CrossRef] 